\title{
Conversion Rate of Laparoscopic Cholecystectomy to Open Surgery at Al Karamah Teaching Hospital, Iraq
}

\author{
Basim Jasim Abdulhussein 1, Yarub Fadhil Hussein ${ }^{2 *}$, Abdulsalam Hatem Nawar2, \\ Redhwan Ahmed Al-Naggar ${ }^{3}$ \\ ${ }^{1}$ Department of Surgery, Al Karamaha Teaching Hospital, Baghdad, Iraq \\ ${ }^{2}$ Department of Urology, Al Karamaha Teaching Hospital, Baghdad, Iraq \\ ${ }^{3}$ Population Health and Preventive Medicine, Faculty of Medicine, Universiti Teknologi MARA, Shah Alam, \\ Malaysia \\ Email: ${ }^{*}$ yarubfadhil@gmail.com
}

Received 25 April 2015; accepted 21 May 2015; published 26 May 2015

Copyright (C) 2015 by authors and Scientific Research Publishing Inc.

This work is licensed under the Creative Commons Attribution International License (CC BY).

http://creativecommons.org/licenses/by/4.0/

(c) †) Open Access

\section{Abstract}

Background: Laparoscopic cholecystectomy has become the standard treatment for symptomatic gall bladder disease. However, there still a substantial proportion of patients in whom Laparoscopic cholecystectomy cannot be successfully performed, and for whom conversion to open surgery is required. Method: In this study, 1600 laparoscopic cholecystectomy performed at $\mathrm{Al}$ karamah teaching hospital from January 2010 to January 2015 , were prospectively analyzed. The patients studied included 1600,1245 where females $(78.4 \%)$ and 346 where males $(21.6 \%)$ with a mean age of 41.2 years. From the data collected, only factors available to surgeon preoperatively were considered for analysis. These factors included: age, gender, history of acute Cholecystitis, jaundice, previous abdominal surgery, obesity and concomitant disease, ultrasound preoperatively \& ERCP. Results: Of the 1600 patients in whom Laparoscopic cholecystectomy was attempted 56 patients $(3.5 \%)$ required conversion to open surgery. The most common reason for conversion was difficult to define anatomy in patients with inflamed, contracted gall bladder $(\mathrm{n}=$ 42). Significant predictor factors for conversion were male gender, previous abdominal surgery, acute Cholecystitis, and obesity. Conclusion: An appreciation for these predictors for conversion will allow appropriate planning by the patient, the institution and the surgeon.

\section{Keywords}

\section{Gall Bladder, Laparoscopy, Cholecystectomy, Open Surgery}

\footnotetext{
${ }^{*}$ Corresponding author.

How to cite this paper: Abdulhussein, B.J., Hussein, Y.F., Nawar, A.H. and Al-Naggar, R.A. (2015) Conversion Rate of Laparoscopic Cholecystectomy to Open Surgery at Al Karamah Teaching Hospital, Iraq. Surgical Science, 6, 221-226. 


\section{Introduction}

Gall stone disease is a common disease affecting human beings. Langenbach in 1892 done the first cholecystectomy [1] but the first successful laparoscopic cholecystecomy was done in 1985 by Eric Muhe. Two years later, Philip Mauret improved the method, over the past two decades, laparoscopic cholecystectomy (LC) has become gold standard for the surgical treatment of gallbladder disease. The advantages of LC over open surgery are a shorter hospital stay, less postoperative pain, faster recovery, better cosmoses [2]. The complications encountered during LC are numerous: some that are specific to this unique technique and some that are common to laparoscopic surgery in general. These include complications related to anesthesia; complications related to peritoneal access (e.g., vascular injuries, visceral injuries, and port-site hernia formation); complication related to pneumoperitoneum (e.g., cardiac complication, pulmonary complications, and gas embolism); and complications related to thrombo-coagulation. Specific complication of LC are hemorrhage, gall bladder perforation, bile leakage, bile duct injury, and perihepatic collection), and others such as external biliary fistula, wound sepsis, hematoma and foreign body inclusions. Some of these complications and several other factors can necessitate the conversion from LC to open cholecystectomy [3]. The conversion from LC to open cholecystectomy results in a significant change in out-come for the patient because of the higher rate of postoperative complications and the longer hospital stay in addition to the effect and the long term sequel of the cause of conversion itself as in bile duct injury [4]. Conversion to open cholecystectomy is occasionally necessary to avoid or repair injury, delineate confusing anatomic relationships, or treat associated conditions [5]. Therefore, aim of this study is to determine the rate of conversion to open cholecystectomy and associated factors.

\section{Methods}

This is a prospective study in Al karamah teaching hospital, Iraq on cases of Laparoscopic cholecystectomy. The aim is to identify the risk factors and the rate of conversion to open cholecystectomy in the period between January, 2010 to January, 2015. There were 1600 cases evaluated under this study.

The preoperative data collected was gender, age, concomitant illness, history of acute cholecystitis and jaundice, previous abdominal surgeries, obesity, ultrasound findings of the gall bladder and preoperative endoscopic retrograde cholangiopancreatatography (ERCP). We classify the patients age as old more than 60 years old \& younger than 60 years old. The body habits of the patients was evaluated by the operating surgeon and classified as (slim, average, obese, morbid obesity), then we classified slim \& average as (non obese) and those of obese \& morbid obesity as (obese), without doing body mass index for those patients.

The previous abdominal surgery was introduced \& classified as non versus any intra abdominal surgery and also divided the previous abdominal surgery to upper abdominal surgery group \& lower abdominal surgery group. The symptoms of the gall bladder were categorized as (non acute) symptoms including biliary colic, chronic dyspepsia, the second group as acute cholecystitis.

The history of Jaundice was analyzed separately to evaluate its effect on the rate of conversion to open surgery. Preoperative biochemical analysis including liver function testes, white blood cells (WBC) was neglected because not all the patients were undergone these testes. The preoperative ultrasound findings regarding the GB wall thickness supposed $(3 \mathrm{~mm})$ thickness as normal and more than $(3 \mathrm{~mm})$ as thick wall. Preoperative ERCP was performed to those patients with jaundice \& CBD stone after performing MRCP (magnetic resonance cholangiopancreatatography) we send the patient to (GIT \& liver center) to perform ERCP \& extracting the CBD stones and then we performed Laparoscopic cholecystectomy. Some patients complain of post Laparoscopic cholecystectomy jaundice with missed CBD stones, those experience post surgery ERCP \& stone clearance were achieved. The operations were performed with the standard four ports and two handed techniques, the surgeons were classified as experienced surgeon who performed more than 20 operations and less experienced surgeon under supervision of the experienced surgeons.

All patients gave informed consent. The study was approved by the ethic committee of Al Karamah teaching hospital.

We estimated that 969 patient is sufficient to detect an estimated prevalence of 3.5\% between any two groups comparison. Allowing for expected 25\% non response rate and multiple comparison, the final sample size to achive a power of 90 was 1600 . Statistical analysis was carried out by means of chi-square test to determine "P” values, and less than 0.05 was accepted as significant. 


\section{Results}

Age and gender distribution with the presenting symptoms are presented in Table 1 . The study records 1254 female (78.4\%) and 346 male (21.6\%) with a mean age of 41.2 years (range 20 - 70 years). Majority were below the age of 60 years. The clinical symptoms were biliary colic 842 patients (52.6\%), acute cholecystitis 121 patients (7.6\%), chronic dyspepsia 620 patients (38.8\%), gall bladder polyps 11 patients and cholecysto-choledocholithiasis 6 patients. Of the 1600 patients in whom laparoscopic cholecystectomy was attempted, 56 patients (3.5\%) required conversion to open surgery.

The reason for conversion to open cholecystectomy was summarized in Table 2. The most common reason for conversion was difficult to define anatomy in patients with inflamed gall bladder $n=42$ (75\%). Laparotomy was required to manage intra operative complications in 14 patients (25\%), in 4 of these patients suspicion of CBD injury, 5 patients there was cystic artery bleeding uncontrolled by Laparoscope, 2 patients there was suspicion of GB cancer and 1 patient there was duodenal injury. No significant relation was found between the likelihood of conversion and any of the following: age, concomitant diseases, preoperative ERCP.

Factors associated with converstion to open cholycystectomy are presented in Table 3 . While significant predictors of conversion to open cholecystectomy were: male gender, previous abdominal surgery, acute Cholecystitis, history of jaundice, and obesity. We analyzed the incidence of Laparoscopic cholecystectomy converted to open surgery in patches of the first 200 cases the conversion rate decreased from $13 \%$ in the first 200 cases to $2.1 \%$ in the remaining 1400 cases, difference that was statistically significant.

\section{Discussion}

Laparoscopic cholecystectomy has become the procedure of choice for management of symptomatic gall blad-

Table 1. Characteristics of the study sample.

\begin{tabular}{|c|c|c|c|}
\hline & & $\mathbf{n}$ & $\%$ \\
\hline Gender & $\begin{array}{l}\text { Female } \\
\text { Male }\end{array}$ & $\begin{array}{c}1254 \\
346\end{array}$ & $\begin{array}{l}78.4 \\
21.6\end{array}$ \\
\hline Age & $\begin{array}{l}>60 \\
\leq 60\end{array}$ & $\begin{array}{c}442 \\
1168\end{array}$ & $\begin{array}{l}27.6 \\
72.4\end{array}$ \\
\hline Biliary colic & $\begin{array}{l}\text { Yes } \\
\text { No }\end{array}$ & $\begin{array}{l}842 \\
758\end{array}$ & $\begin{array}{l}52.6 \\
47.4\end{array}$ \\
\hline Acute cholecystitis & $\begin{array}{l}\text { Yes } \\
\text { No }\end{array}$ & $\begin{array}{c}121 \\
1479\end{array}$ & $\begin{array}{c}7.6 \\
92.4\end{array}$ \\
\hline Chronic dyspepsia & $\begin{array}{l}\text { Yes } \\
\text { No }\end{array}$ & $\begin{array}{l}620 \\
980\end{array}$ & $\begin{array}{l}38.8 \\
61.2\end{array}$ \\
\hline Gall bladder polyp & $\begin{array}{l}\text { Yes } \\
\text { No }\end{array}$ & $\begin{array}{c}11 \\
1589\end{array}$ & $\begin{array}{c}0.4 \\
99.6\end{array}$ \\
\hline cholecysto-choledocholithiasis & $\begin{array}{l}\text { Yes } \\
\text { No }\end{array}$ & $\begin{array}{c}6 \\
1594\end{array}$ & $\begin{array}{c}0.7 \\
99.3\end{array}$ \\
\hline Concomitant diseases & $\begin{array}{c}\text { Present } \\
\text { Not present }\end{array}$ & $\begin{array}{c}564 \\
1046\end{array}$ & $\begin{array}{l}35.2 \\
64.8\end{array}$ \\
\hline Previous abdominal surgery & $\begin{array}{l}\text { Upper abdominal surgery } \\
\text { Lower abdominal surgery } \\
\text { No abdominal surgery }\end{array}$ & $\begin{array}{c}25 \\
319 \\
1266\end{array}$ & $\begin{array}{c}1.5 \\
19.9 \\
78.6\end{array}$ \\
\hline History of jaundice & $\begin{array}{l}\text { yes } \\
\text { No }\end{array}$ & $\begin{array}{c}41 \\
1559\end{array}$ & $\begin{array}{c}2.6 \\
97.4\end{array}$ \\
\hline Obesity & $\begin{array}{l}\text { Yes } \\
\text { No }\end{array}$ & $\begin{array}{l}724 \\
876\end{array}$ & $\begin{array}{l}45.3 \\
54.7\end{array}$ \\
\hline Gall bladder wall on ultrasound & $\begin{array}{l}\text { Thick } \\
\text { Normal }\end{array}$ & $\begin{array}{c}347 \\
1253\end{array}$ & $\begin{array}{l}21.7 \\
78.3\end{array}$ \\
\hline Preoperative ERCP & $\begin{array}{l}\text { Yes } \\
\text { No }\end{array}$ & $\begin{array}{c}6 \\
1594\end{array}$ & $\begin{array}{c}0.4 \\
99.6\end{array}$ \\
\hline Required conversion & $\begin{array}{l}\text { Yes } \\
\text { No }\end{array}$ & $\begin{array}{c}56 \\
1544\end{array}$ & $\begin{array}{r}3.5 \\
96.5\end{array}$ \\
\hline
\end{tabular}


Table 2. Reason for conversion to open cholecystectomy.

\begin{tabular}{ccc}
\hline Reason & n & \% \\
\hline Difficult to define anatomy & 42 & 75.00 \\
Suspicion of CBD injury & 4 & 7.14 \\
Duodenal injury & 1 & 1.79 \\
Cystic artery bleeding & 5 & 8.93 \\
Cystic duct injury & 2 & 3.57 \\
Suspicion of gall bladder cancer & 2 & 3.57 \\
Total & 56 & 100 \\
\hline
\end{tabular}

CBD: Common Bile Duct.

Table 3. Factors associated with conversion to open cholycystectomy.

\begin{tabular}{|c|c|c|c|c|c|c|}
\hline \multirow{2}{*}{\multicolumn{2}{|c|}{ Variable }} & \multicolumn{2}{|c|}{ No Conversion } & \multicolumn{2}{|c|}{ Conversion } & \multirow{2}{*}{$\mathrm{p}$} \\
\hline & & $\mathrm{n}$ & $\%$ & $\mathrm{n}$ & $\%$ & \\
\hline \multirow{2}{*}{ Gender } & Female & 1228 & 97.9 & 26 & 2.1 & \multirow{2}{*}{$<0.001$} \\
\hline & Male & 316 & 90.5 & 30 & 9.5 & \\
\hline \multirow{2}{*}{ Age } & $>60$ & 424 & 95.8 & 18 & 4.2 & \multirow{2}{*}{0.642} \\
\hline & $\leq 60$ & 1130 & 96.6 & 38 & 3.4 & \\
\hline \multirow{2}{*}{ Concomitant diseases } & Present & 548 & 97.1 & 16 & 2.9 & \multirow{2}{*}{0.083} \\
\hline & Not present & 1006 & 96.0 & 40 & 4.0 & \\
\hline \multirow{3}{*}{ Previous abdominal surgery } & Upper abdominal surgery & 20 & 75.0 & 5 & 25.0 & \multirow{3}{*}{$<0.001$} \\
\hline & Lower abdominal surgery & 304 & 95.1 & 15 & 4.9 & \\
\hline & No abdominal surgery & 1230 & 97.1 & 36 & 2.9 & \\
\hline \multirow{2}{*}{ Acute cholecystitis } & \multirow{2}{*}{$\begin{array}{l}\text { Yes } \\
\text { No }\end{array}$} & 114 & 93.9 & 7 & 6.1 & \multirow{2}{*}{$<0.001$} \\
\hline & & 1430 & 96.6 & 49 & 3.4 & \\
\hline \multirow{2}{*}{ History of jaundice } & Yes & 37 & 89.2 & 4 & 10.8 & \multirow{2}{*}{$<0.001$} \\
\hline & No & 1507 & 96.5 & 52 & 3.5 & \\
\hline \multirow{2}{*}{ Obesity } & \multirow{2}{*}{$\begin{array}{l}\text { Yes } \\
\text { No }\end{array}$} & 684 & 94.2 & 40 & 5.8 & \multirow{2}{*}{$<0.001$} \\
\hline & & 860 & 98.1 & 16 & 1.9 & \\
\hline \multirow{2}{*}{ Gall bladder wall on ultrasound } & Thick & 335 & 96.6 & 12 & 3.4 & \multirow{2}{*}{0.972} \\
\hline & Normal & 1209 & 96.5 & 44 & 3.5 & \\
\hline \multirow{2}{*}{ Preoperative ERCP } & Yes & 4 & 66.7 & 2 & 33.3 & \multirow{2}{*}{$<0.001$} \\
\hline & No & 1540 & 96.6 & 54 & 3.4 & \\
\hline
\end{tabular}

ERCP: Endoscopic retrograde cholangiopancreatography.

der stone disease [6]-[10]. The advantages to the patient and the economic benefits to society have been reported [11]. However the risk of conversion to open surgery is always present. The actual rates of conversion reported in the literatures are quite variable [6]-[10] ranging from $0 \%$ to $20 \%$.

In our study the conversion rate was $3.5 \%$ of the 1600 attempted Laparoscopic cholecystectomies. Although conversion to open surgery is not a complication, laparotomy is associated with greater morbidity and prolonged 
convalescence than laparoscopy. Therefore, understanding the risk of conversion allows the patient to make a better informed decision about surgery.

From the surgeons' perspective, understanding the factors associated with an increased likelihood of conversion allows more objective selection of patients. The risk of conversion is related to surgeon factors, and possibly equipment factors. The surgeon experience is very important.

In our study, the conversion rate was $13 \%$ in the initial 200 patients and $2.1 \%$ in the remaining 1400 patients. Most of the conversions the reason was anatomic difficulty related to inexperience of the surgeon. Early in a surgeon experience with laparoscopic cholecystectomy, patient selection is likely to be more restricted. In these early cases, surgeon would benefit from having a good idea preoperatively about predictors of an "easy"case as compared with a case more likely to require conversion.

The decision about when to convert to laparotomy is an individual one, often subjective, made by the surgeon in the course of the procedure. In our study, the main reason for conversion was inability to define the anatomy clearly (42 from 56), this finding was noted in similar studies [12]-[14]. The reasons for difficulty in exposing the anatomy were presence of acute cholecystitis, thickened gall bladder wall, obesity, and adhesions resulting from previous abdominal operations.

Acute cholecystitisis accompanied by increased vascularity and dense adhesions that interfere with good visualization, whereas thick walled gall bladder often is shrunken and contracted. In both presentations the cystic duct becomes foreshortened, and the gall bladder may be adherent to the common bile duct, making it difficult to grasp the gall bladder for retraction or to dissect the gall bladder from the common bile duct.

Patients who have undergone abdominal surgery where found to have increased difficulty during Laparoscopy in terms of adhesions in the upper abdomen. There were more conversion rate in upper abdominal surgery (20\%) comparing to lower abdominal surgery (4.7\%). This is because of many adhesions attached to area of gall bladder surgery and to the anterior abdominal wall, but we believe that with increased experience, surgeons would overcome this difficulty.

Explanations for the higher conversion rate in obese patients include difficult Trocar placement, obscure anatomy because of excessive intra peritoneal fat, and inability to retract the liver sufficiently. However, these problems can be overcome with improvements in Laparoscopic instruments. In this study, male gender was found to be associated with increased risk of conversion, the rate being $2.07 \%$ in women and $8.9 \%$ in men, and the reason why men have a higher conversion rate is not clear.

History of jaundice, is associated with high conversion rate, this may suggest that the gall bladder was complicated, and this may lead to difficult anatomy exposure. In conclusion, the reported data have shown that significant predictors of conversion are male gender, previous abdominal surgery especially upper abdominal surgery, acute cholecystitis, history of jaundice, thickened gall bladder wall by Ultrasound, obesity and the experience of the surgeon.

Two limitations worth mentioning that may affect interpretation of the results. First, that data comes from one centre which may limit generalization of the results. Secondly, data about BMI was not collected and the obesity classification was made subjectively by the surgeon.

\section{Conclusion}

An appreciation for these predictors of conversion will allow appropriate planning by the patient, the institution and the surgeon.

\section{References}

[1] Bittner, R. (2006) Laparoscopic Surgery: 15 Years after Clinical Introduction. World Journal of Surgery, 30, 11901203. http://dx.doi.org/10.1007/s00268-005-0644-2

[2] Reynolds, W. (2001) The First Laparoscopic Cholecystectomy. JSLS, 5, 89-94.

[3] Shamiyeh, A. and Wayand, W. (2004) Laparoscopic Cholecystectomy: Early and Late Complications and Their Treatment. Langenbeck's Archives of Surgery, 389, 164-171. http://dx.doi.org/10.1007/s00423-004-0470-2

[4] Sicklick, J.K., Camp, M.S., Lillemoe, K.D., Melton, G.B., Yeo, C.J., Campbel, K.A., et al. (2005) Surgical Management of Bile Duct Injuries Sustained during Laparoscopic Cholecystectomy. Annals of Surgery, 241, 786-795. http://dx.doi.org/10.1097/01.sla.0000161029.27410.71

[5] Tayeb, M., Raza, S.A., Khan, M.R. and Azami, R. (2005) Conversion from Laparoscopic to Open Cholecystectomy: 
Multivariate Analysis of Preoperative Risk Factors. Journal of Postgraduate Medicine, 51, 234-238.

[6] Cushier, A., Dubois, F., Moniel, J., Mouret, P., Becher, H., Buess, G., Trede, M. and Traidl, H. (1991) The European Experience with Laparoscopic Cholecystectomy. American Journal of Surgery, 161, 385-387. http://dx.doi.org/10.1016/0002-9610(91)90603-B

[7] Deizel, D.D., Millikan, K.W. and Airan, M.C. (1993) Complications of Laparoscopic Cholecystectomy: A National Survey of 4292 Hospitals and Analysis of 77,604 Cases. American Journal of Surgery, 165, 9-14. http://dx.doi.org/10.1016/S0002-9610(05)80397-6

[8] Scott, T.R., Zucker, K.A. and Boiley, R.W. (1992) Laparoscopic Cholecystectomy: A Review of 12,397 Patient. Surgical Laparoscopy, Endoscopy, 3,191-198.

[9] (1991) Southern Surgeon Club a Prospective Analysis of 1518 Laparoscopic Cholecystectomies. New England Journal of Medicine, 324, 1073-1078. http://dx.doi.org/10.1056/NEJM199104183241601

[10] Wolfe, B.M., Gardiner, B.N., Leary, B.F. and Frey, C.F. (1991) Endoscopic Cholecystectomy: An Analysis of Complications. Archives of Surgery, 126, 1192-1198. http://dx.doi.org/10.1001/archsurg.1991.01410340030005

[11] Burkun, J.S., Burkun, A.N., Samplis, J.S., Fried, G., Taylor, B., Wevler, M.J., Goresky, C.A. and Meakins, J.L. (1992) Randomized Controlled Trial of Laparoscopic versus Minicholecystectomy. Lancet, 340, 1116-1119. http://dx.doi.org/10.1016/0140-6736(92)93148-G

[12] Liu, C.-L., Fan, S.-T., Lai, E.C., Lo, C.-M. and Chu, K.-M. (1996) Factors Affecting Conversion of Laparoscopic Cholecystectomy to Open Surgery. Archives of Surgery, 131, 98-101.

[13] Fried, G.M., Burkan, J.S. and Meakins, J.L. (1994) Factors Determining Conversion to Laparotomy in Patient Undergoing Laparoscopic Cholecystectomy. American Journal of Surgery, 167, 35-41. http://dx.doi.org/10.1016/0002-9610(94)90051-5

[14] Peters, J.H., Krailadsiri, W., Incorbene, R., Bremner, C.G., Froes, E., Ireland, A.P. and Stain, S.A. (1994) Reason for Conversion from Laparoscopic to Open Cholecystectomy in an Urban Teaching Hospital. American Journal of Surgery, 168, 555-559. http://dx.doi.org/10.1016/S0002-9610(05)80121-7 